\title{
Use of Community Cultural Practices and Beliefs in the Conservation of Lake Baringo Ecosystem in Kenya
}

\author{
Ming'ate Mogambi Lamech Felix ", Karigu Mary \\ Department of Environmental Studies and Community, Kenyatta University, Nairobi, Kenya \\ Email address: \\ mingate.felix@ku.ac.ke (M. M. L. Felix), mogambimingate@yahoo.com (M. M. L. Felix) \\ ${ }^{*}$ Corresponding author
}

\section{To cite this article:}

Ming'ate Mogambi Lamech Felix, Karigu Mary. Use of Community Cultural Practices and Beliefs in the Conservation of Lake Baringo Ecosystem in Kenya. International Journal of Natural Resource Ecology and Management. Vol. 3, No. 3, 2018, pp. 32-38.

doi: 10.11648/j.ijnrem.20180303.11

Received: January 18, 2018; Accepted: February 1, 2018; Published: July DD, 2018

\begin{abstract}
Cultural practices and beliefs are closely linked to biodiversity conservation. The paper presents an analysis of information collected from three indigenous communities (Ichamus/Njemps, Pokots and Tugen) living in Lake Baringo ecosystem, Kenya. We argue that community cultural practices and beliefs have an impact in the conservation of ecosystems such as that of Lake Baringo. Descriptive survey method where semi-structured questionnaires were administered to household heads was used to collect data. Qualitative, participant observation and recording of key informants were also used in data collection. The data collected was guided by the Ecosystem Services (ES) framework. Analysis was done using a combination of descriptive and content analysis. The analysis shows that cultural practices and beliefs have some positive and negative impacts in the conservation of an ecosystem. It is recommended that cultural practices and beliefs may be useful in the conservation of an ecosystem but care must be taken to ensure that those culture practices that are not compatible with ecosystem management are eliminated.
\end{abstract}

Keywords: Community, Cultural Practice and Belief, Conservation, Lake Baringo, Kenya

\section{Introduction}

The importance of biodiversity cannot be emphasized as it is well revealed by its intrinsic value, use to humans and in maintenance of resilience for the natural environment (Geseret. al., 2009; Hassan et. al., 2005). Ecosystem health is a critical precondition for good human health and sustainable livelihoods necessary for achieving sustainable development (Hassan et al., 2005; Geseret al., 2009). However, biodiversity degradation has been reported to be common in developing countries where majority of the population's livelihoods depend on ecosystem services (Donohoe, 2003). For instance despite the fact that lakes provide a source of livelihood for majority of rural people in Africa, they are severely faced by degradation (Hassan et al., 2005; Lockwood, 2000). Lake Baringo ecosystem in Kenya is one such lake whose survival is seriously threatened by degradation with substantial quantity of the vegetation cleared (Akivagaet al., 2010). It is faced with water quality degradation, sedimentation, land use changes and uncontrolled. d abstraction of water which has impacted negatively on its biodiversity (Ballot et al., 2003; Akivagaet al., 2010).

Several measures including policies and laws have been set up as an effort to sustainably use and conserve Lake Baringo (Ballot et al., 2003) e.g theFisheries Act Cap 378 of 1989 whichillegalizes immature fishing (GoK, 1989). However, these policies and laws have not resulted in substantial success in conserving this resource (Ballot et al., 2003). Furthermore, in Kenya, most of its population consists of small holder farmers and fishermen (Donohoe, 2003). These populations has further led to increased unsustainable extraction and use of natural resources including forests, land, water and atmosphere thus affecting the ecosystem (Hassan et al., 2005).

In line with the forgoing degradation challenges, Onyando et al., (2005), did a study in Lake Baringo and they recommend that there is need to come up with innovative and collaborative ways of conserving this lake. In addition, (Rappaport, 2000) argue that culture is one element which 
may provide an essential avenue to the communities living near Lake in conserving its biodiversity. The dominant ethnic groups (Tugen, Pokot and Ichamus) living in Lake Baringo ecosystem have been identified to have a rich culture (Odada, Onyando and Aloo 2004). Odada, Onyando and Aloo (2004) further acknowledge that customary practices play a role in biodiversity conservation of ecosystems. They point out that socio-cultural factors including cultural practices, beliefs and perspectives and stratification of the communities may contribute to degradation of lakes such as Baringo. Culture is a set of control mechanisms, plans, recipes, rules and instruments for the governing of behavior (Geertz, 1973). Alcamo et al., (2003) defines cultural services in terms of the nonmaterial benefits people obtain from ecosystems, and specifically lists cultural diversity, spiritual and religious values, knowledge systems, educational values, inspiration, aesthetic values, social relations, sense of place, cultural heritage values, recreation and ecotourism.

In understanding how the cultural practices and beliefs impacts in the conservation of lake Baringo ecosystem, the study wasguided by the Ecosystem Services (ES) framework (Alcamo et al., 2003). This framework has emerged as a formal approach to describe and categorize the relationship between ecosystems and society, and it is widely accepted within the international environmental science and policy communities (Daniel et al., 2012). The services provided by ecosystems have been classification as: provisioning services (e.g., food, fresh water), regulating services (e.g., climate regulation, water purification), cultural services (e.g., aesthetic, spiritual, recreational experiences), and supporting services (e.g., nutrient cycling, soil formation). Basic provisioning services are widely recognized as essential for meeting human needs for nutrition, shelter, and safety. Regulating services are more complex but have been brought to public attention by discussions of climate change and recent natural disasters. Supporting services are fundamental to all other services, but their relationship to human needs can be indirect and complex (Daniel et al., 2012). It is argued in the paper that community cultural practices and beliefs have an impact in the conservation of ecosystems such as that of Lake Baringo (Mascia, et al., 2003). It is good to note that we did not use the ecosystem services guidelines in verbatim but rather we used them to help us understand on what we expect to do when collecting culture related data.

\section{Methodology}

The study was conducted in Baringo County which was purposively sampled as it hosts Lake Baringo which has experienced serious environmental degradation in the past few years (Aloo, 2002). (Figure. 1). In particular the study was interested in understanding the cultural practices and beliefs of three indigenous communities (Ichamus/ $\mathrm{Njemps,}$ Pokots and Tugen) living in Lake Baringo ecosystem
These ethnic groups believe in God and supernatural beings. Although nowadays the majority of the members of Tugen, Ichamus and Pokot have accepted Christianity as their religion, some people still adhere to traditional beliefs (Mukadi, et al., 2015). It is worth noting that even the converted Christians still hold onto their traditional beliefs and practices. Traditionally the Pokot people believed in a God called Tororot while the Njemps and Tugen believed in a God called Asis (Kaendi, 1994).

The culture of these ethnic groups is also marked by strong attachment to livestock where livestock such as cattle, sheep and goats form a significant feature of their culture. The cattle are particularly significant as they are viewed as a source of wealth and act as a traditional currency in marriage ceremonies including dowry payments (Mukadi, et al., 2015). Besides, the culture of the three ethnic groups is marked by gender differentiation of roles. Men are traditionally assigned the role of being the protectors of their families and property in the Tugen, Pokot and Njemps ethnic groups ensuring their safety from attacks by external aggressors (Kaendi, 1994). This role is assumed by young men immediately after undergoing initiation. On the other hand, women are the caretakers of their families where they undertake domestic chores and also provide labor in the farms (Kaendi, 1994).

Agriculture is a fundamental economic activity that marks the culture the communities living in Baringo County though the members of the ethnic groups engage in different economic activities. The Tugen living in the highlands such as Tugen hills practice cultivation of crops such as coffee and food crops while the Pokot practice pastoralism keeping large herds of livestock. On the other hand, the Njemps are basically fisher folk with some of them being farmers (Kaendi, 1994). The members of all the three ethnic groups also engage in other economic activities such as beekeeping and tourism. The ethnic groups' food includes blood; milk and meat this makes them to have a special attachment to livestock. Therefore it is common for Pokot people to attack their neighboring communities including Tugen and Turkana in order to enlarge their herds (Juma, 2000).

This research utilized descriptive survey method. Semistructured questionnaires were administered to household heads to collect data on study issues. Inaddition, qualitative research was conducted through face to face interviews that were conducted with a diverse range of key informants, including community leaders religious leaders, beach management committee members, Staff from the Ministry of Agriculture, Livestock and Fisheries and the Ministry of Environment and Natural Resources. This method allowed for probing of in-depth information and was used to explore the environmental cultural practices and perspectives of the indigenous communities in Lake Baringo ecosystem (Table. 1). 


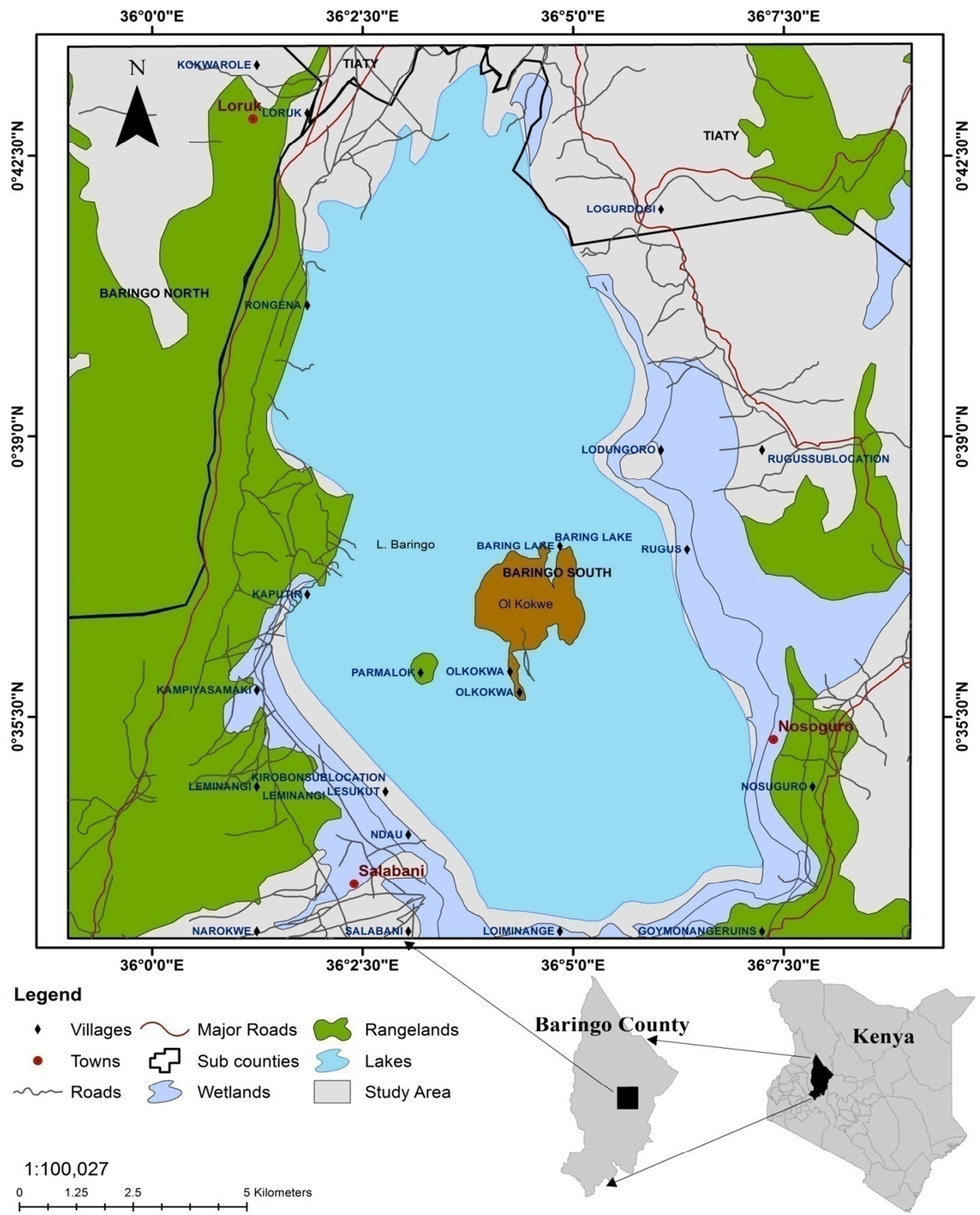

Figure 1. Study area Location.

Table 1. Study respondents.

\begin{tabular}{llll}
\hline S/N & Type of instrument & Type of respondent & Number of interviews (n) \\
\hline 1 & Semi-structured questionnaire & Household heads & 378 \\
& & Community leaders & 5 \\
& & Religious leaders & 5 \\
2 & Interview schedule & Beach Management committee members & 2 \\
& & Staff member- Ministry of Agriculture, Livestock and Fisheries & 1 \\
& & Staff member- Ministry of Environment and Natural Resources & 1 \\
\hline
\end{tabular}


Data was also collected from secondary sources such as internet, journals and on-on-line books through literature search/review.

Analysis from the household heads was done using a combination of contentanddescriptive analysis which utilized the Statistical Package of Social Sciences (SPSS). Content analysis was utilized for the secondary sources of data because the approach is flexible, its ability to focus on specific research questions and extraction of in-depth information form sensitive topics (Elo, et al., 2014). While all the qualitative data that emanated from the semi-structured interviews and the key informants was transcribed grouped into similar themes and used to answer the study objectives.

\section{Results and Discussions}

This study sought to understand theimpact of cultural practices and beliefsof the ethnic groups living in Lake Baringoon the ecosystem. We argue in this paper that community cultural practices and beliefs have an impact in the conservation of ecosystems such as that of Lake Baringo. To address this objective, the study concentrated on some activities done by the communities in relation to conservation of the Lake Baringo ecosystem namely: attachment to livestock and ecosystem conservation, belief in religion, God and sacred places of worship and ecosystem conservation, plant species with cultural and spiritual value to the ethnic groups and environmental conservation. Most of these activities have cultural values attached to them.

\subsection{Activities Carried Around Lake Baringo}

To put the study into perspective we asked our respondents to identify the activities being carried around Lake Baringo The study found that (Table 1). Majorityabout 193 (51\%) of the respondents practice pastoralism, 98 (26\%) practice fishing while $38(10 \%)$ of them are farmers. The communities also utilize the Lake and its ecosystem for tourism 38 (10\%) activities such as rafting. Bee keeping is also an emerging economic activity that is being practiced by a small group11 (3\%) of residents in Lake Baringo ecosystem.

Table 2. Natural utilization ways of the respondents.

\begin{tabular}{lll}
\hline Natural utilization way & Frequency & Percentage \\
\hline Pastoralism & 193 & 51 \\
Fishing and related business & 98 & 26 \\
Farming & 38 & 10 \\
Tourism & 38 & 10 \\
Bee-keeping & 11 & 3 \\
Totals & 378 & 100 \\
\hline
\end{tabular}

\subsection{Attachment to Livestock and Ecosystem Conservation}

We asked our respondents how the cultural attachment to cattle has impacted on the conservation of Lake Baringo Ecosystem. We found that thecattle in Lake Baringo Ecosystem are viewed as a major source of wealth and serves as a form of traditional currency used to bargain for wives and payment of dowry (Mukadi, et al., 2015). Cattle also have ritual importance where they are offered to ancestral spirits during sacrifices (Berkes (2008).

According to a key Tugen community leader, the Pokot ethnic group is aggressive in enlarging their herds a factor that results to frequent conflicts over pastures and water resources. As the informant put it:

Young men from the Pokot community attack us from time to time and steal our cattle, goats and sheep. They also attack our community and the Njemps when their animals lack pasture and water; they invade our land to get pasture and water.

They believe that conflict over the resources due to cattle is justified as cattle are given to them by God (Schilling et al., 2012). This keeping of large herds of livestock puts pressure on the pastures and water resources resulting to unsustainable management of resources (Schilling et al., 2012).

\subsection{Belief in Religion, God and Sacred Places of Worship and Ecosystem Conservation}

Through qualitative interviews with the key religious informant leaders from the study communities reported thattraditionally, the Pokotcommunity called their God "Tororot", the Tugenand Njemps communities' call him "Asis" andthat most community members have adopted Christianityand they believe in a supernatural God. The leaders reported:

Most of my community members are Christians who believe in the teachings of the bible, but they also believe in the God of our forefathers-Pokot religious leader

My community has adopted Christianity to a great extent, but we still believe in the God of our ancestors whom we call Asis- Tugen religious leaders.

We as the Njemps, believe in God, the Father, Son and Holy Spirit but we still believe in the God of our forefathersNjemps religious leaders

According to the key community leader's informants, up to date the communities also have sacred places of worship where they believe that particular forests and hills are holy and that they are the dwelling places of their God. One such hill is called Morop and Tugen hills where the community elders go to worship gods in times of disasters such as drought:

My community members believe that the God of our ancestors live in special forests and hills such as Morop and Tugen hills where weelders go to pray to him- A Tugen religious leader

Elders of our land visit certain forests and mountains to offer sacrifices to the ancestral spirits- A Pokot community leader

The communities refer to a hilltop specially set aside for worship as "Kaapkoros". These holy hills and forests are habitats of native herbs used for local purposes including medicinal, social, and religious purposes. As such these natural resources are preserved by the community (Kakudidi, 
2004). The common belief in a religion provides values that guide and regulate utilization, conservation and management of resources (Adzobu, Okeame \& Peter, 2011).

Additionally, the key religious leader's informants also confirmed that, the ethnicgroup's belief in a supreme God who is all powerful and controls the universe has made the community to implement bio-centric attitudes and instill in their generations a behavior of conserving the environment as a result of the intrinsic value attached to natural environment (Adzobu, Okeame \& Peter, 2011).

We believe in the God of our ancestors and the Holy Trinity who created the world and man and placed man in the earth to take care of it

The study also found that, religion has a central role to play in the formulation and the articulation of ethics that guide community behavior and management of the environment (Awolalu2006; Mary \& John, 2009; Shastri, 2002; Smith \&Wishnie, 2000; Enejiet al., 2012).

\subsection{Plant Species with Cultural and Spiritual Value to the Ethnic Groups and Ecosystem Conservation}

The study also revealed that the three ethnic groups living in Lake Baringo ecosystem have various plant species that are of cultural value to their members. Plants are used by the communities for (i) medicine; Parts of plants such as leaves, bark, roots are prepared by experienced medicine men e.g by crushing and boiling and administered either orally or by applying on affected part of the body e.g on a skin cutfor treatment of various diseases such as those shown in (Table 2
\& 3); (ii) social structure (ceremonies such as weddings, during birth and naming of children where millet and sorghum are served as food either as porridge or as traditionally prepared beer) (iii) religion (Elders pray and offer sacrifices under certain trees that are considered sacred such as Euphorbia tirucalli, Mormodicafoetidaschumach, Ficussycomorusand Ficuscarica, or Ficusthonningii (referred to as Simotwo in Pokot) among the Pokot ethnic group. Sacred offerings being offered to God and gods are tied on sticks harvested from sacred trees). This species are highly protected.

Several plant species also play a cultural and symbolic role in the lives of the Tugen, Njemps and Pokot community members. Some plants such as Bersamaabyssinica (Kaptalilet in Tugen) are used to protect community members against witchcraft. It is also a taboo to use some of the trees for firewood and therefore such trees are never cut. One such tree is Erythrinaabyssinica (Kokkowoin the Pokot) ethnic group and when it falls it is curved into various traditional items for instance bowls (Kakudidi, 2004). A Tugen community key informant summed this finding:

We have plants that we use for medicine and other social uses like in protection from witchcraft. We plant these plants in our homesteads and when we cut trees in the forest, we don't cut them.

The study showed that the Tugen community has various medicinal plants that they use for treatment of various diseases such as Malaria (Esse) and Leishmaniasis (Munguti, 1997) (Table 2).

Table 3. Medicinal plants among the Tugen Community.

\begin{tabular}{llll}
\hline Number & Plant species (Tugen language) & Botanical name & Disease \\
\hline 1. & Chepking'un & Momordicafriesiorum & Malaria \\
2. & Seketet & Myrsineafricana & Malaria \\
3. & Kibulwa & Gardenia ternifolia & Malaria \\
4. & Sok & Warburgiaugandensis & Malaria \\
5. & Anon & Manilkarabutugi & Malaria \\
6. & Muarubaine & Azadirachtaindica & Malaria \\
7. & Arwa & Tamarindusindica & Malaria \\
8. & Kipchepkwere & Harrisoniaabyssinica & Malaria, Typhoid \\
9. & Kosirich & Gomphocarpusfruticosus & Malaria, Typhoid \\
10. & Ngwadere & Ajugaremota & Malaria \\
11. & Tilomwo & Ziziphusmucronata & \\
\hline
\end{tabular}

The study established that the Njemps community also has plants that are of cultural values. One such shrub is called "ambach" plant which provides"ambach" wood used in making boats used for moving around the lake during fishing. This plant is protected among the community members enhancing plant diversity.

In addition, the study revealed that the Pokot community also has some knowledge of herbal remedies and have various medicinal plants used for treatment of ailments and diseases (such as Leishmaniasis, wounds and cuts) and in stimulating increased milk and meat in livestock (Kaendi, 1994). Some of the plants that have medicinal value in the Pokot community include (Table 3 ).

Table 4. Medicinal plants among the Pokot community.

\begin{tabular}{llll}
\hline Number & Plant Species (Pokot language) & Botanical Name & Disease \\
\hline 1. & Kerelwo & Crotolariadichogamus & Wounds \\
2. & Muikutwe & Garciniajonstonii & Leishmaniasis \\
3. & Kimira & Croton incana & Stomach upsets \\
4. & Kalobotwo & Solanumincanum & Milk secretion \\
5. & Ngopkwo & Acacia mellifera & Cuts \\
\hline
\end{tabular}




\subsection{Initiation Rites as a Cultural Value for Environmental Conservation}

It was found that the three communities practice initiation rites of both girls and boys. Majority of the members (94\%) from the Tugen, Njemps and Pokot indicated that it is a requirement for young girls and boys in their community to undergo initiation and join an age set system (Figure 2) (Rappaport, 1999, 2000)

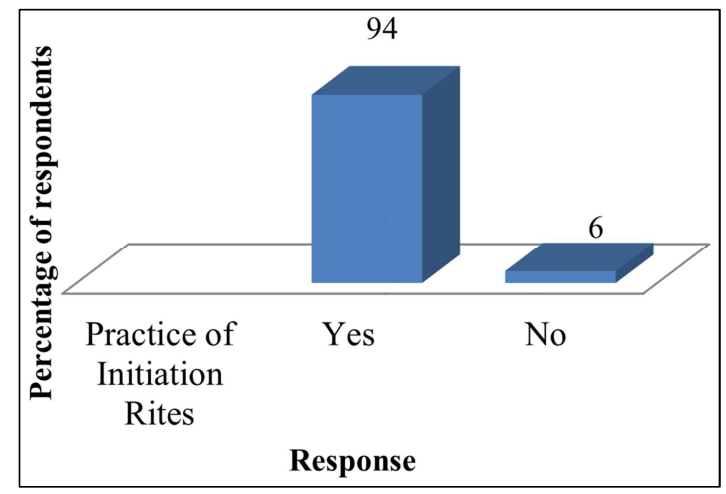

Figure 2. Practice of initiation rites.

During initiation and marriage, young people are trained by the elders to be responsible adults and members of the community and to preserve the communities' cultural heritage and wealth. Most community members (63\%) teach their children on various issues including environmental conservation and ethics including using services such as water and forests (Aubel, 2010). Some rites such as initiation are performed near the rivers or in the forests. The ecosystem is therefore preserved by both young and old generations. According to a community key informant:

It is a catastrophe to answer a short call or defecate in the rivers (Aubel, 2010).

Majority (59\%) of the children and young people know their cultural. This can be attributed to the fact that most of the adults transmit indigenous knowledge and cultural values, beliefs and practices to the young generation through various methods including storytelling, myths, songs and dances. This is a good indication that young people are a viable target group that should be targeted for environmental conservation initiatives through channels such as education and cultural festivities.

\section{Summary and Recommendations}

The aim of the paper was to understand the impact of cultural practices and beliefs in the conservation of Lake Baringo Ecosystem. The study shows that cultural practices and beliefs have some positive and negative impacts in the conservation of an ecosystem. Firstly, some cultural practices such as keeping of large herds of livestock puts pressure on the pastures and water resources resulting to unsustainable management of resources (Schilling et al., 2012). Secondly, religion has a central role in guiding community behavior in the management of an ecosystem (Awolalu 2006; Mary \& John, 2009; Shastri, 2002; Smith \& Wishnie, 2000; Enejiet al., 2012). Thirdly, the indigenous knowledge and cultural values, beliefs and practices transmitted to the young generation through various methods including storytelling, myths, songs and dances is important in helping the conservation of an ecosystem. It is recommended that cultural practices and beliefs may be useful in the conservation of an Ecosystem but care must be taken to ensure that those cultural practices that are not compatible with ecosystem management are eliminated.

\section{Conclusion}

It is concluded that cultural practices and beliefs have some positive and negative impacts in the conservation of an ecosystem. Thus governments may consider a communities culture and beliefs in conserving ecosystems.

\section{References}

[1] Adzobu, C. D., Okeame, A. A., \& Peter, G. V. (1991). Religious beliefs and environmental protection: the Malshegu sacred grove in northern Ghana. Washington. DC, USA: World Resources Institute and Nairobi. Kenya: Acts Press. African Centre for Technology Studies.

[2] Akivaga, E. M., Otieno, F. A., Kipkorir, E. C., Kibiiy \& Shitote, S. (2010). Impact of introducing reserve flows on abstractive uses in water stressed Catchment in Kenya: Application of WEAP21 model. International Journal of the Physical Sciences. Vol. 5 (16), pp. 2441-2449, December 4th, $2010 . \quad$ Available online athttp://www.academicjournals.org/IJPS.

[3] Alcoma, J., Neville J. Ash, Colin D. Butler, J. Baird Callicott, Doris Capistrano, Stephen R. Carpenter...et al, 2003). Ecosystems and Human Well-Being. A Framework for Assessment. Washington, DC: Island Press.

[4] Aubel, J. (2010). "Elders: a cultural resource for promoting sustainable development" The Grandmother project. UK: World Watch Institute book publishers.

[5] Awolalu J. O. (2006). What is African Traditional Religion? Studies in Comparative Religion, Vol. 10, No. 2. World Wisdom, Inc. Available at www.studiesincomparativereligion.com.

[6] Ballot, A., Pflugmacher, S., Wiegand, C., Kotut, K., \& Krienitz, L., (2003). Cyanobacterial toxins in Lake Baringo. Kenya: Limnologica Publishers.

[7] Berkes, F. (2 Ed.). (2008). Sacred ecology; Traditional ecological knowledge and resource management. Philadelphia PA: Taylor \& Francis.

[8] Berkes, F. (2001). Religious traditions and biodiversity. In Encyclopedia of Biodiversity (Vol. 5, pp. 109-120). Chicago: Biodiversity Encyclopedia.

[9] Berkes, F. (2004). Rethinking community-based conservation. Conservation Biology, (Vol. 18, pp. 621-630). Basingstoke, UK: Macmillan Education Ltd. 
[10] Braun, V., \& Clark, V. (2012). Thematic analysis. In H. Cooper, P. M. Camic, D. L. Long, A. T. Panter, D. Rindskopf, \& K. J. Sher (Eds.), A handbook of research methods in psychology (Vol. 2, pp. 57-71. http://dx.doi.org/10.1037/13620-004). Washington, DC: American Psychological Association.

[11] Britton, J. C., Jackson M. C., Muchiri M., Tarras-Wahiberg H., Harper D. M. \& Grey J. (2009). Status, Ecology and Conservation of an Endemic Fish, Oreochromisniloticusbaringoensis, in Lake Baringo. Nairobi: Macmillan Publishers.

[12] Elo, S., Kääriänen, M., Kanste, O., Pölkki, T., Utriainen, K., \& Kyngäs, H. (2014). Qualitative content analysis: A focus on trustworthiness. SAGE Open, 1-10. DOI: $10.1177 / 2158244014522633$.

[13] Eneji, C. V., Ntamu, G. U., Unwanade, C. C., Godwin, A. B, Bassey, J. E., Willaims, J. J \& Joseph, I. (2012). Traditional African Religion in Natural Resources Conservation and Management in Cross River State, Nigeria. Environment and Natural Resources Research; Vol. 2, No. 4; 2012.

[14] Geertz, C. (1973) The Interpretation of Culture: Selected Essays. New York, Basic Books.

[15] Harmon D. (2002). In Light of Our Differences. Washington DC: Smithsonian Institution Press.

[16] Juma, M. K. (2000). Unveiling Women as Pillars of Peace Peace Building in Communities Fractured by Conflict in Kenya: An interim Report on Management and Government Program, New York: UNDP, 2000.

[17] Kaendi, J. M. (1994). Coping with malaria and visceral leishmaniasis (kala-azar) in Baringo District, Kenya: Implications for disease control in California Los Angeles. Nairobi: Macmillan publishers.

[18] Kakudidi, E. K. (2004). Cultural and Social Uses of Plants from and around Kibale National Park, Western Uganda. African Journal of Ecology, Afri. J. Ecol., 42 Vol. 1:114-118.

[19] Kiriro K. (2011). The Gikuyu Marriage. Nairobi: Longhorn Publishers (U) Ltd.

[20] Mascia, M. B., J. P. Brosius, T. A. Dobson, B. C. Forbes, L. Horowitz, M. A. McKean and N. J. Turner. (2003). Conservation and the social sciences. Conservation Biology 17 (3):649-650.
[21] Milfont, T. L., Duckitt, J. \& Cameron, L. D. (2006). A CrossCultural Study of Environmental Motive Concerns and Their Implications for Pro-environmental Behavior. Environment and Behavior. November 2006 vol. 38 no. 6 745-767. doi: $10.1177 / 0013916505285933$.

[22] Mukadi, E. B., Kiptiony, G. J. \& Sindabi, M. (2015). Tugen Men and Women's Perception on FGM in Relation to their Participation in Household and Community Socioeconomic Development Activities in BaringoCounty. Kabarak j. res. innov. 3 No. 1, pp. 21-31.

[23] Mustafa, M. \& Young, C. (2003). "Pastoral Politics in Northern Kenya's Pokot People", National Geographic 161 $\wedge \$((1)$, pp. $120-140$.

[24] Nyakayo, A. O. \& Njeru, P. K. (2013). National Disaster Management Authority, Baringo County. Rapid Flood Assessment Report (7-8 ${ }^{\text {th }}$ ) August, 2013.

[25] Odada, E., Onyando, J. \& Aloo, P. O. (2004). Experience and Lessons Learned Brief for Lake Baringo. Nairobi: Macmillan Publishers.

[26] Omwega, A. \& fNorgbeys, S. (2004). Lake Baringo community based land and waterManagement. UNEP Evaluation Report. Nairobi: Jomo Kenyatta Foundation.

[27] Rappaport, R. A. (2000). Pigs for the Ancestors: Ritual in the Ecology of a New Guinea People. Long Grove: Waveland Press.

[28] Schilling, J., Opiyo F. E, \& Scheffran J. (2012). Raiding Pastoral Livelihoods: Motives and effects of violent conflict in North Western Kenya. Pastoralism: Research, Policy and practice $\quad 2$ : $25 \quad$ Available at http://www.pastoralismjournal.com/content/2/1/25.

[29] Shastri, C. M., Bhat, D. M., Nagaraja, B. C., Murali, K. S., \& Ravindranath, N. H. (2002). Tree species diversity in a village ecosystem in Uttara Kannada district in Western Ghats, Karnataka. Current Science, 82, 1080-1084.

[30] Smith, E. A., \& Wishnie, M. (2000). Conservation and subsistence in small-scale societies. AnnualReviewsAnthropology, 29,493524.http://dx.doi.org/10.1146/annurev.anthro. 29.1.49. 